Medicine Updates Faculty of medicine https://muj.journals.ekb.egdean@med.psu.edu.eg April 2022, volume 9, issue 9

\title{
" Utilization of quality tools to prevent unnecessary prescriptions of Antibiotics in hospitals"
}

\section{$\underline{\text { Authors }}$}

Saad Ahmed Abdel Aziz Allam 1; Alshimaa Mohamed Sabry²; Mohamed Hosny Habashy³ ${ }^{3}$ Maisara Ibrahim Alameldeen ${ }^{4}$; Salma Nasser Nour ${ }^{5}$; Nada Elsayed Elsamahy ${ }^{6}$; Mohamed Ahmed Elkiky7; Dina Mohamed Elsayd $^{8}$; Ahmed Mohamed Nageeb ${ }^{9}$

\footnotetext{
${ }^{1}$ Faculty of pharmacy, Tanta university, Tanata, Egypt.

${ }^{2}$ Quality manager @pharmacist samar abdelrahman medical unit.

${ }^{3}$ (pharmacist at Ali Ibn Abi Taleb medical center, Port said

${ }^{4}$ Quality manager at Ali Ibn Abi Taleb medical center, Port said

${ }^{5}$ Salma Nasser Mohamed Nour - pharmacist

${ }^{6}$ (laboratory chemist at Ali Ibn Abi Taleb medical center, Port said

${ }^{7}$ Dentist \&amp; amp; Health information in information systems department of General authority of health care branch in portsaid

${ }^{8}$ Enviroment and safty facility manager at pharmacist samar abdalrahman medical unit)

${ }^{9}$ (Member of quality team at Port fouad 2 health unit
} 


\section{Introduction}

Prevention of unnecessary prescriptions of antibiotics in hospital is one of the hottest topics in daily medical filed. The Centers for Disease Control and Prevention (CDC) and the World Health Organization (WHO) are important health organizations which have been sounding the alarm on the dangers of antibiotic resistance for years, it may have had little effect on how often antibiotics are doled out. There is a new study in the Unites States was issued January 16 in the BMJ, its content that Nearly 25 percent of antibiotic prescriptions are unnecessary in the United States. [1]

Many guidelines published highlight when we need antibiotics and when we don't. For instance, antibiotics can cure bacterial infection but viral infections like the common cold, antibiotic cannot cure. Therefore, it is not helpful to prescribe it in these situations.

Moreover, overuse of antibacterial drugs makes people at risk for a prevented side effects.

Centers for Disease Control and Prevention and The Pew Charitable Trusts has published new research, that shows nearly one third of prescribed antibiotics at hospital, emergency room, and is unnecessary, about 50 million prescriptions every year. [2] The most common causes of antibiotic overuse or overprescribing are:

-misdiagnosis.

-the doctors do not follow up on the updates of guidelines.

-lack of experience.

Risks of antibiotic overworked contain not only bacterial resistance towards certain antibiotics, but also increase in disease acuteness, disease duration, patient complications and adverse effects, risk of death, healthcare expenses, and need for medical treatment of health issues which may have resolved. [3]

\section{Aim of the work}

Antibiotics are significant medications. If we proceed in unnecessary use, we will have to fight bare-hand many life-threating infections. So, in our research, we performed a systemic review and quantitative analysis to assess effectiveness of quality improvement to avoid unnecessary prescription of antibiotics.

Strategies to reduce antibiotics prescription for acute outpatient illness for which antibiotics are inappropriately prescribed. The reduction in number of un necessary prescription of antibiotics has become one of the most important objectives for PHC. In our research, we use quality tools to prevent unnecessary prescription of antibiotics.

\section{These tools are:}

Brain storming, Multiple voting, Priority matrix, Fish bone, Pareto chart.

\section{Review of literature}

Antibiotics are important drugs. It has many benefits, especially penicillin in curing hazard microbial infections, stopping the spread of many communicable disease and minimizing most 
of complications of many diseases. Recently, many antibiotics are non-effective or un-useful. [4]

Recently, antibiotic resistance is the major dilemma in medical sciences because the rising number of its cases. New resistance species are existing and increasing worldwide, making treatment of common infectious diseases like pneumonia, tuberculosis, gonorrhea a complicated process. .... etc. [5]

So, what should you do to minimize the hazard of bacterial resistance, keep these tips in mind:

- Take antibiotics only for bacterial infections. Ask your physician to decide if an illness is "mild" or not before starting treatment course of antibiotics. Even if the symptoms don't get worse but do last a while.

- Seek advice and ask questions. Ask your physician about whether your illness is bacterial or viral infection, and discuss the risks and benefits of antibiotics.

- Ask physician about how to treat the uncomfortable symptoms, as a stuffy nose or scratchy throat

- The duration of treatment plan recommended by doctors must be followed exactly. [6]

\section{Methodology}

\section{Brain storming}

Brainstorming is a creative method used in quality management and is an effective quality tool that enhance good thinking and stimulate ideas generation. Atmosphere free from critics and judgment is important in success of brain storming.

\section{Principles of brain storming}

$\star$ reduce social inhibitors among group of people.

$\star$ Increase creativity in the group.

Why we use this method?

To generate high volume of ideas (larger number of ideas) to help achieving success. In order to manage this method and achieve good result, Ideas should be documented. For instance, In Ali is Abi Talib medical center, we find some problems and we do our best to resolve it and do improvement

$\star$ A) Narrow area in pharmacy.

$\star$ B) slowness of system.

$\star$ C) few numbers of pharmacists in comparison with number of patients.

$\star$ D) information system is not used to arrange flow of patient to pharmacy.

$\star$ E) unnecessary prescription of antibiotics.

From the previous, we find that (Unnecessary prescription of antibiotics) is the most sensitive problem that need solution.

\section{MULTPLE VOTING}

This method provide technique to decreasing a large list of ideas to smaller list which contain the best ideas with most priority. It also can decrease the list to just one single idea. By this method, the idea that is favored by the members of the group will be in the top.[7] 
Why we use Multi Voting method?

Multi voting method is a decision-making tool, can be used after Brain Storming tool which provide a large number of ideas.[8]

The advantages of Multi Voting method are:

Easy, simple straight tool and doesn't take long time.[7]

After brain storming results, we used multiple voting to determine the priority of problems

The priorities of the choice depending on:

- Their effect on the patient safety and health.

- Frequency of the problem.

- Cost of the solve.

- The easiest to solve.

- Time consuming to solve.

\begin{tabular}{|l|l|l|l|l|l|}
\hline $\begin{array}{l}\text { Priority of } \\
\text { choice }\end{array}$ & $\underline{\mathbf{1} \text { mark }}$ & $\underline{\mathbf{2} \text { marks }}$ & $\underline{\mathbf{3} \text { marks }}$ & $\underline{\mathbf{4} \text { marks }}$ & $\underline{\mathbf{5} \text { marks }}$ \\
\hline $\begin{array}{l}\text { effect on the } \\
\text { patient safety } \\
\text { and health }\end{array}$ & No effect & Minor effect & $\begin{array}{l}\text { Moderate } \\
\text { effect }\end{array}$ & $\begin{array}{l}\text { effect on the } \\
\text { patient safety } \\
\text { and health } \\
\text { and has no } \\
\text { effect on } \\
\text { plane of care }\end{array}$ & $\begin{array}{l}\text { The most } \\
\text { effect on the } \\
\text { patient safety } \\
\text { and health } \\
\text { and has effect } \\
\text { on plane of } \\
\text { care }\end{array}$ \\
\hline $\begin{array}{l}\text { Frequency of } \\
\text { reptation of } \\
\text { the problem. }\end{array}$ & No repetition & rare & minor & moderate & $\begin{array}{l}\text { The most } \\
\text { repetitions }\end{array}$ \\
\hline $\begin{array}{l}\text { Cost of the } \\
\text { solve. }\end{array}$ & Very high cost & High cost & Moderate cost & Low cost & No cost \\
\hline $\begin{array}{l}\text { The easiest to } \\
\text { solve }\end{array}$ & $\begin{array}{l}\text { The most } \\
\text { complicate }\end{array}$ & complicate & moderate & minor & $\begin{array}{l}\text { Easiest to } \\
\text { solve }\end{array}$ \\
\hline $\begin{array}{l}\text { Time } \\
\text { consuming to } \\
\text { solve. }\end{array}$ & $\begin{array}{l}\text { Very long time } \\
\text { (months) }\end{array}$ & $\begin{array}{l}\text { Long time (1 } \\
\text { month) }\end{array}$ & $\begin{array}{l}\text { Moderate } \\
\text { (2weeks to 1 } \\
\text { month }\end{array}$ & $\begin{array}{l}\text { Short time (1 } \\
\text { week to 2 } \\
\text { weeks) }\end{array}$ & $\begin{array}{l}\text { Very Short } \\
\text { time } \\
\text { (Less than a } \\
\text { week) }\end{array}$ \\
\hline
\end{tabular}

Multiple voting is doing to select problems with high priority by the members as flowing:

\begin{tabular}{|c|c|c|c|c|c|c|c|c|c|}
\hline Problems & $\begin{array}{c}\text { Member } \\
\text { (A) }\end{array}$ & $\begin{array}{c}\text { Member } \\
\text { (B) }\end{array}$ & $\begin{array}{c}\text { Member } \\
\text { (C) }\end{array}$ & $\begin{array}{c}\text { Member } \\
\text { (D) }\end{array}$ & $\begin{array}{c}\text { Member } \\
\text { (E) }\end{array}$ & $\begin{array}{c}\text { Member } \\
\text { (F) }\end{array}$ & $\begin{array}{c}\text { Member } \\
\text { (G) }\end{array}$ & $\begin{array}{c}\text { Member } \\
\text { (H) }\end{array}$ & TOTAL \\
\hline A & $\underline{11}$ & $\underline{11}$ & $\underline{13}$ & $\underline{10}$ & $\underline{14}$ & $\underline{10}$ & $\underline{11}$ & $\underline{8}$ & $\underline{88}$ \\
\hline B & $\underline{10}$ & $\underline{12}$ & $\underline{9}$ & $\underline{14}$ & $\underline{10}$ & $\underline{14}$ & $\underline{11}$ & $\underline{12}$ & $\underline{92}$ \\
\hline C & $\underline{15}$ & $\underline{13}$ & $\underline{10}$ & $\underline{12}$ & $\underline{15}$ & $\underline{17}$ & $\underline{10}$ & $\underline{11}$ & $\underline{107}$ \\
\hline D & $\underline{18}$ & $\underline{17}$ & $\underline{14}$ & $\underline{15}$ & $\underline{17}$ & $\underline{15}$ & $\underline{12}$ & $\underline{14}$ & $\underline{126}$ \\
\hline E & $\underline{\mathbf{2 1}}$ & $\underline{\underline{22}}$ & $\underline{14}$ & $\underline{15}$ & $\underline{\mathbf{2 3}}$ & $\underline{15}$ & $\underline{17}$ & $\underline{15}$ & $\underline{154}$ \\
\hline
\end{tabular}


1- Unnecessary prescriptions of antibiotics (doses, duration or description in prescription) according to the medical center static last 3 months

2- Information system is not used to arrange flow of patients to pharmacy

\section{Priority matrix}

This method used to recognize which problem has the priority and importance to solve first.[9]

This method can be used by any person, single individual or large organization and from simple task to complexed process.[10]

Priority Matrix can take different forms depending on the criteria complexity to define the most priority.

\begin{tabular}{|c|c|c|c|c|c|c|}
\hline problem & $\begin{array}{c}\text { Frequency } \\
\text { of the } \\
\text { problem. }\end{array}$ & $\begin{array}{c}\text { The easiest } \\
\text { to solve }\end{array}$ & $\begin{array}{c}\text { Cost of the } \\
\text { solve. }\end{array}$ & $\begin{array}{c}\text { effect on } \\
\text { the patient } \\
\text { safety and } \\
\text { health. }\end{array}$ & $\begin{array}{c}\text { Time } \\
\text { consuming } \\
\text { to solve }\end{array}$ & TOTAL \\
\hline A & 3 & 1 & 1 & 1 & 1 & 7 \\
\hline B & 2 & 1 & 3 & 2 & 3 & 11 \\
\hline C & 2 & 3 & 4 & 2 & 1 & 12 \\
\hline D & 3 & 4 & 4 & 1 & 4 & 16 \\
\hline E & 3 & 5 & 5 & 5 & 2 & 20 \\
\hline
\end{tabular}

The result of the priority matrix is compatible with the multiple voting and confirms that the most important problems to sole are:

3- Unnecessary prescriptions of antibiotics (doses, duration or description in prescription) according to the medical center static last 3 months

4- Information system is not used to arrange flow of patients to pharmacy

\section{Flowchart}

Flowcharts are used in documenting and designing simple procedures. They help expressing what is happening and also determining any process. Flowchart has two main box types which are:

Firstly, Activity that is a processing step, and drawn as a rectangular box. Secondly, A decision, drawn as a diamond.

\section{How to design a Flow chart}

1. Finding the purpose of the process. What we need to achieve? Details is very important thing in any research.

2. Ordering the steps in timeframe. These steps or tasks may be communicating with participants, reviewing any documentations. Then writing the steps in a notebook, then starting building the chart.

3. Use the shape of each step to organize them correctly, for instance process, decision, inputs or outputs. 
4. Designing the chart, we can draw it by hand or using a program.

5. Confirming step, review all steps with the process owners. [12]

This method was used in the Ali Bin Abi Talib Center in Port Said, and the Quality Committee in the center, during its meeting, determined the basic steps included in the problem in question.

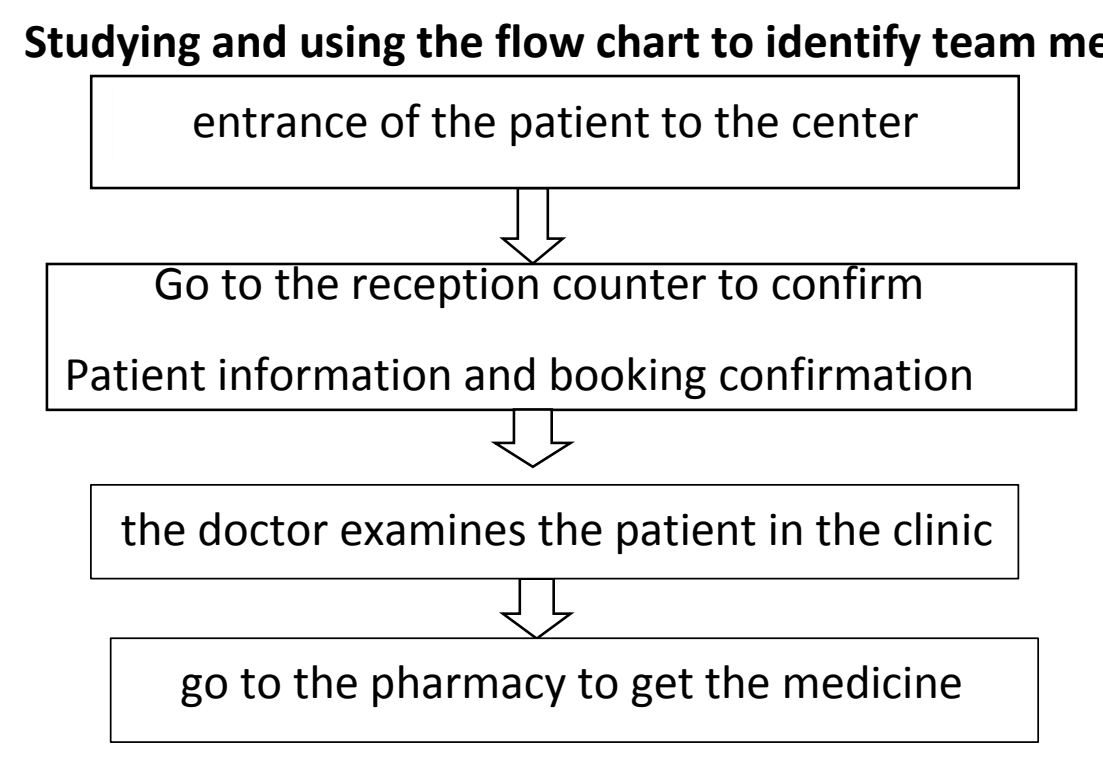

Based on the above clarification, an administrative order has been issued to form the improvement team responsible for solving the problem mentioned and made up of the following

\begin{tabular}{|l|l|l|}
\hline Name & specialization & Role in the team \\
\hline Dr/ Mohamed Hosny & Chief pharmacist & Leader \\
\hline Dr/ Maisara Alam Eldin & Head of quality department & Time arrangement \\
\hline Dr/Abd Elrahman Awad & Pharmacist- & member \\
\hline Dr/ Mina Alfy & pharmacist & member \\
\hline Dr/Ahmed Abd el Aziz & Medical director & member \\
\hline Mrs/ Marwa Hassan & $\begin{array}{l}\text { Head of system and information } \\
\text { department }\end{array}$ & member \\
\hline
\end{tabular}

\section{Fish bone}

\section{understand the root cause of the problem using cause and effect diagram}

Root cause analysis is a structured team process that helps in finding underlying causes of an adverse reaction or a problem or even near-miss. Knowing the role of root causes in system failure can assist developing correction actions. FISHBONE diagram (CAUSE AND EFFECT diagram) is used in brain storming process to help the team to discover the main causes of any problem by categorizing the ideas in a useful way during brainstorming process. It differs from other tools used in brainstorming to identify root causes such as Five Whys tool. This tool drawn in Fishbone-like diagram where the problem is displayed at the front part (the fish head). Potential causes are put on the smaller "bones" on the fish body under different cause categories. [13] 


\section{Fishbone tool}

It has other names such as "cause-and-effect diagram", "Ishikawa diagram" [14]

Reverse fishbone diagram. The fishbone identifies multiple causes for an effect or problem. Brainstorm technique needs fishbone in its steps. It organizes ideas into useful categories. [14] Uses: identifying any causes for a problem or dilemma. Fish bone procedures [14]

1. Identify the problem (effect). Write the problem on a whiteboard. Draw square around it and draw a horizontal lines or arrows running to it.

2. Using the Brainstorming tool to categorize the possible causes of the problem according to the following categories: Methods, Machines, Manpower, Materials, Measurement, Environment.

3. Writing these categories of causes as branches from the primary arrow.

4. Use Brainstorming again to find all possible causes of the problem. We must Ask questions like "Why does this effect exist?" and the answer is written in each category. Each Cause can be written in different category if it belongs to many categories.

5. Then, Writing the sub-causes. We continue to ask "Why?" until going deeper to find out all associated causes for the problem.

\section{Patient workplace environment}

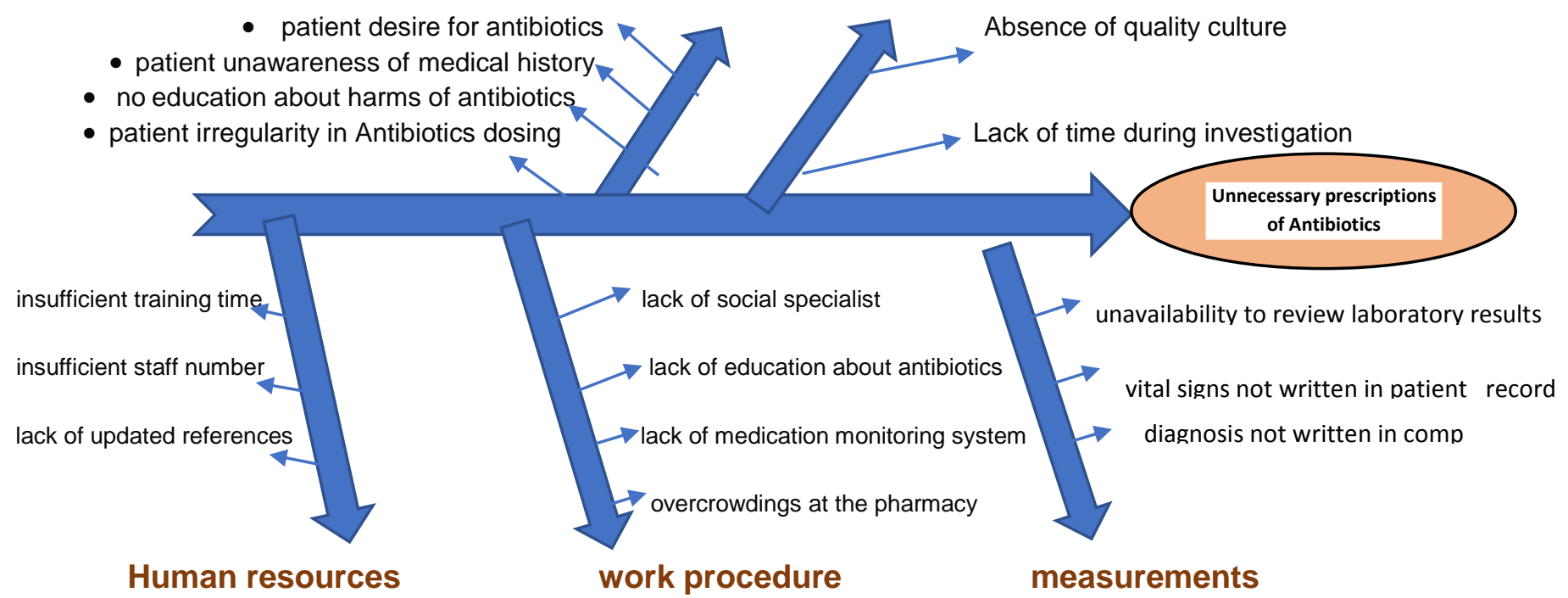

Here Performance improvement team will start data aggregation in order to identify the most common causes for this deviation, and to exclude the rarely happened causes

Here, data aggregation source will be:

- Patient complaints

- OVR

- Personal interview with patients

- Phone calls

- Patient survey

After data collection we will use another tool of quality which is 


\section{Pareto chart}

- Originally, the chart is named for Vilfredo Pareto, an Italian economist, he found the idea that $20 \%$ of the causes generate $80 \%$ of results.

- In other words, problems will have different impact on each process, so it is best to first concentrate on the most important.

- The Pareto helps the organizations to understand that most outcomes result from minor incomes.

- A Pareto chart is a type of chart which consists of bars graph and a line graph, where bar graph are

- viewed in descending order, and the total cumulative percentage is represented by the line.

- The purpose of the Pareto chart is to identify the common cause or source of problem. In quality control, Pareto charts are useful to prioritize in order to observe the most overall improvement, the highest occurring type of defect, or the most frequent reasons for patient complaints. focus on problems with greatest potential for improvement

\begin{tabular}{|c|c|c|c|c|}
\hline Symbol & Cause & frequency & percentage & cumulative percentage \\
\hline A & Lack of ongoing medical training for health practitioners & 32 & $33 \%$ & $33 \%$ \\
\hline B & guidelines Lack of updated and approved clinical practice & 28 & $29 \%$ & $62 \%$ \\
\hline C & flow system (Q. System) malfunction Patient & 8 & $8 \%$ & $70 \%$ \\
\hline D & There is no medical director & 6 & $6 \%$ & $76 \%$ \\
\hline $\mathbf{E}$ & $\begin{array}{l}\text { regarding the number of health care providers is Insufficient } \\
\text { volume of customers }\end{array}$ & 6 & $6 \%$ & $82 \%$ \\
\hline $\mathbf{F}$ & Absence of social specialist & 4 & $4 \%$ & $87 \%$ \\
\hline G & $\begin{array}{l}\text { patients urged the health care providers to prescribe Some } \\
\text { actual need antibiotics without any }\end{array}$ & 3 & $3 \%$ & $90 \%$ \\
\hline H & doses Patient irregularity in taking medications & 2 & $2 \%$ & $92 \%$ \\
\hline I & Lack of medical education & 1 & $1 \%$ & $93 \%$ \\
\hline J & $\begin{array}{l}\text { medication In many cases the patient did not recognize } \\
\text { history }\end{array}$ & 1 & $1 \%$ & $94 \%$ \\
\hline K & Consultation interval is not sufficient & 1 & $1 \%$ & $95 \%$ \\
\hline $\mathbf{L}$ & No appropriate space of time for training & 1 & $1 \%$ & $96 \%$ \\
\hline M & pharmacists Viewing lab results is not available for the & 1 & $1 \%$ & $97 \%$ \\
\hline $\mathbf{N}$ & spread of blame culture and the absence of a quality & 1 & $1 \%$ & $98 \%$ \\
\hline 0 & Incomplete diagnosis in patient medical records & 1 & $1 \%$ & $99 \%$ \\
\hline \multirow[t]{2}{*}{$\mathbf{P}$} & Absence of a drug tracking system & 1 & $1 \%$ & $100 \%$ \\
\hline & & 97 & $100 \%$ & \\
\hline
\end{tabular}

\section{- Uses of Pareto Chart}

- For analyzing data about the frequency of problems or causes in a process

- For focusing on the most significant causes.

- For analyzing causes by detecting their specific components.

- For communicating with others about your data. In this performance improvement project, we will plot the aggregated data in pareto table to draw pareto chart 


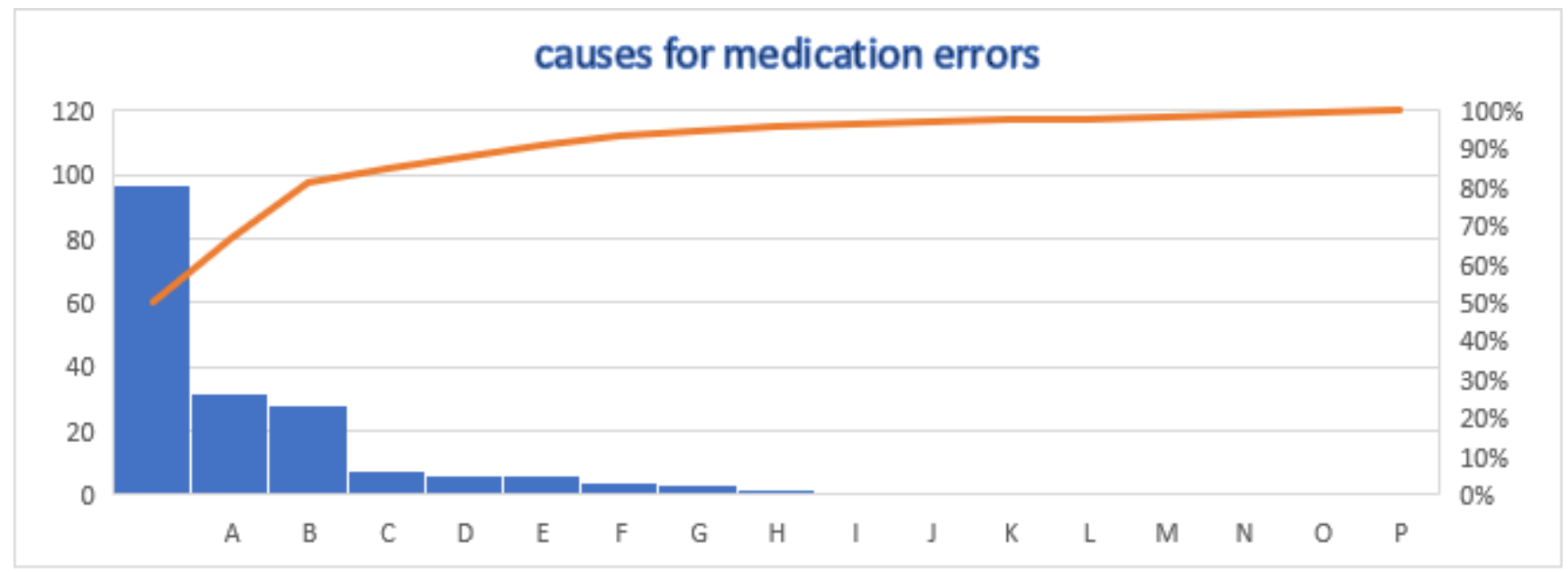

\section{Results}

From using quality tools to find the main causes of unnecessary prescription of antibiotics we found the following results:

- By using multiple voting, we found that the most problem need to be solved is that the information system is not used to arrange the flow of patients to pharmacy

- Then we used priority matrix to recognize the problem that needs to solve first we found that the results of priority matrix are compatible with the results of multiple voting which is that the information system is not used to arrange the flow of patients to pharmacy

Then we used fish bone tool for more understanding of the root causes of the unnecessary prescription of antibiotics and we have many causes:

- Lack of continuous education for physicians

- Absence of updated medical protocols to guide doctors through their diagnosis

- Patient flow system malfunction

So, we used Pareto chart to find out the most significant cause of this problem and to find the problem that need to be solved first we found that almost over one quarter of the problem was

\section{Because of:}

- Lack of continuous education for physicians

- Absence of updated medical protocols to guide doctors through their diagnosis

\section{Discussion}

From the above findings and results we can say that the main causes for unnecessary prescription of antibiotics is:

- lack of continuous education for physicians.

- Absence of updated medical protocols to guide doctors through their diagnosis.

Here it is an opinion against our findings

David Hyun, M.D., works on The Pew Charitable Trusts' antibiotic resistance project wrote:

The causes of inappropriate prescription of antibiotics can be summarized in the next five causes.

- Patients and their family requests. Patients may plan to have a prescription at any visit, whether or not an antibiotic is useful. Also, doctor may expect that. researches showed pressure 
from patients and their relatives has an effect on doctors' decision and this will lead them to recommend antibiotics.

- Time limited. In hospital clinics, physicians have limited visit duration to see their patients, diagnose illnesses, and implement a treatment plan. studies revealed that physicians may prescribe antibiotics easily to avoid discussion about antibiotics resistance.

- Decision fatigue. Diagnosing and seeing growing numbers of patients may affect a doctor's decisions. For instance, a recent study showed that during workdays, healthcare practitioners became more likely to recommend antibiotics to patients with acute respiratory infections.

- Doubtful diagnoses. Here is similarity between bacterial and viral infections symptoms such as cough, sore throat. So, it is difficult for doctors to differentiate between them. In these situations, physicians may prescribe antibiotics because they believe that risk of not prescribing them is more than unnecessary antibiotic use.

- Considering that other physicians are the dilemma. although doctors agree that antimicrobial overuse is a big dilemma, they don't think that neither their practices nor those of their peers in the same medical specialty, contribute to this problem. Studies showed that physicians blame other branches of medicine for inappropriate prescription of antibiotics. [12]

Understanding the reasons for unnecessary antibiotic prescribing can help in the development of antibiotic stewardship. And some researchers have already started stewardship strategies, with some positive results. [15]

\section{Conclusion}

Antimicrobial resistance has now gained the attention of influential international health care groups, despite being ignored for a long time. antibiotic resistance is one of the main microbial threats to health in the world and humans must decrease the inappropriate use of antibiotics. We can increase patient safety and comfort as part of our daily practice. Reduce the waste of important resources by taking care of them. as well as lowering resistance [16]

This offered an environment in which we could examine the behaviors that contribute to antibiotic misuse and find gaps in the response. Finally, we offer a set of viable behavioral science interventions that are both complimentary to current tactics and have a solid theoretical basis for their mechanism of action. Naturally, there is no proof of costeffectiveness in lowering antibiotic resistance for these innovative or upgraded therapies, so they must be tested in practice. [17]

From our research we can concluded the flowing:

1- Antibiotics are critical medication should be taken under physician's control.

2- Undesirable use of antibiotics can cause antibiotic resistance.

The following reasons must be pursued because they are the main reason for the increase in antibiotic resistance, namely:

1- Lack of continuous education for physicians

2- Absence of updated medical protocols to guide doctors through their diagnosis

\section{Recommendations}

The unnecessary prescription of Antibiotics and the wrong use and over use of anti-biotic in human and animal as well as low infection control leads to increase the level of anti-biotic resistance there are several results appear from this problem such as high medical costs and 
long hospital stays and increase mortality rate the control of the problem start from individuals/policy maker/health professionals/health care industry/agriculture sector. [18]

\section{The individual should}

1- Use antibiotic that prescribed only by the physician according to the case.

2-Not take any antibiotic without need and avoid sharing or using over antibiotic

3-Follow hygienic ways in food and drink to reduce bacterial infection.

\section{Policy makers in health organizations should}

1- Apply programs and plans that ensure the control of infection in the place and minimize the rate of prescription of unnecessary anti-biotic and antibiotic resistance.

2-Policy makers should collect information's about anti-biotic and determine the ways to use and disposal of medicine.

\section{Health professional s should}

1-ensure sterilization of the place and instruments and working in clean environment to inhibit spread of bacteria.

2- Give the information to the patient how about to use the antibiotic and the danger of misuse of it and prescribe the anti-biotic to patient according to the case.

3-Talking to the patient to increase immunity by use vaccines and hand washing and wearing face mask.

\section{$\underline{\text { In Agriculture field }}$}

1-animals also use antibiotics under veterinary opinion.

2-prevent the use of antibiotic to promote growth.

3-Give necessary vaccines to animals to decrease the usage of anti-biotic.

Apply quality processes in all steps of production of food and drink that come from animal or plant sources

Health care industry should continue in researches to develop new generations of anti-biotic and vaccines.

\section{Summary}

Lack of updated guidelines, misdiagnosis and lack of continuous education are the most common causes for unnecessary prescription of antibiotics. we designed a review and quantitative analysis to evaluate effectiveness of quality improvement process to avoid unnecessary prescription of antibiotics. for generating high volume of ideas, we chose to perform Brainstorming technique to find out the main problem. Then, using cause and effect diagram to find out the root causes for over prescription of Antibiotics. Finally, we used Pareto Chart to focus on the right cause to start with. The causes were:

- Lack of experience for physicians due to inactivity of continuous medical education.

- Absence of updated medical protocols to guide doctors through their diagnosis.

- Patient flow system malfunction. 
Other finding from David Hyun, M.D., works on The Pew Charitable Trusts' antibiotic resistance project say that causes for high number of antibiotic prescriptions unnecessarily were: Patients and their family pressure, Time limited, Decision fatigue, Uncertain diagnoses or other doctors are the problem.

Antibiotics are critical medication should be taken under physician's control. Undesirable use of antibiotics can cause antibiotic resistance. Based on our research results, we advise that:

1- Doctors are the only persons who entitled to prescribe Antibiotics.

2- Following good hygiene in daily life activities.

3- People should not share antibiotics together.

4- Patients' education about antibiotics is a must.

5- Using Personal protection aides.

6- Ensuring high level of sterilization in hospitals.

7- People must follow Vaccination schedules for their children.

\section{References}

1- www.healthline.com/health-news/25-percent-antibiotic-prescriptions-unnecessary

2- https://www.pewtrusts.org/en/research-and-analysis/articles/2017/06/30/why-doctors-prescribe-antibioticseven-when-they-shouldnt

3- https://www.cidrap.umn.edu/asp/overuse-overprescribing-of-antibiotics.

4- https://www.mayoclinic.org/healthy-lifestyle/consumer-health/in-depth/antibiotics/art-20045720

5- https://www.who.int/news-room/fact-sheets/detail/antibiotic-resistance

6- https://www.rchsd.org/health-articles/the-danger-of-antibiotic-overuse/

7- https://digital.ahrq.gov/health-it-tools-and-resources/workflow-assessment-health-it-toolkit/all-workflowtools/multivoting

8- https://asq.org> quality-resources

9- https://uihc.org> Asset-3733....DOC

10- https://www.process.st/prioritization-matrix/

11- [5] SEVOCAB: Software Systems Engineering Vocabulary. Term: Flow chart. Retrieved 31 July 2008.

12- [6] https://www.lucidchart.com/pages/what-is-a-flowchart-tutorial.

13- https://www.cms.gov/medicare/provider-enrollment-andcertification/qapi/downloads/fishbonerevised.pdf

14- https://asq.org/quality-resources/fishbone

15- https://www.pewtrusts.org/en/research-and-analysis/articles/2017/06/30/why-doctors-prescribe-antibioticseven-when-they-shouldnt

16- https://www.ncbi.nlm.nih.gov/pmc/articles/PMC3203003

17- https://www.gov.uk/government/publications/antibiotic-prescribing-and-behaviour-change-inhealthcare-settings

18- http://www.who.int/news-room/fact-sheets/detail/antibiotic-resistance. 